\title{
Silent design of electric motors: optimization under constraints and parameters uncertainties
}

\author{
M. Jeannerot, J.-B. Dupont, E. Sadoulet-Reboul, M. Ouisse, V. Lanfranchi, P. Bouvet
}

\begin{abstract}
This paper describes an optimization methodology dedicated to the minimization of the noise and vibrations in electric motors. It relies on a numerical workflow which is described in this paper, coupling models belonging to the fields of electromagnetics, structural dynamics and acoustics. Afterwards, a deterministic optimization method is described and applied to au tomotive traction motors. As the optimization of electric motors aims at manufacturing motors which are silent when operated, an enhancement of the optimization to consider the effect of manufacturing tolerances, materials properties dispersion and con trol uncertainties on the vibratory or acoustic levels to minimize is finally described and this robust optimization method is applied on a practical case.
\end{abstract}

Index Terms-Acoustics, Design Optimization, Electric Motors, Electromagnetics, Robustness, Vibrations.

\section{NOMENCLATURE}

PWM: Pulse Width Modulation.

PMSM: Permanent Magnet Synchronous Motor.

IPMSM: Interior Permanent Magnet Synchronous Motor. e.o.: Engine order

\section{INTRODUCTION}

To estimate the noise radiated by an electric motor numerically, methods performing a weak coupling between electromagnetic, dynamic and acoustic models are frequently applied to diverse motor technologies [1]-[5]. These methods offer good accuracy when compared with meas urements [6, and they enable for the estimation of the level of noise radiated by any design. In the context of computing power increase, some minimization algorithms can be used in order to modify the electric motors design so as to minimize the radiated noise estimated using the multiphysical workflow, while ensuring, by means of optimization constraints, that overall electromechanical performance criteria, such as mean torque, torque ripple or efficiency, are not deteriorated. Using this method, several automotive traction motors have been optimized, achieving significant nois e level reductions, owing to the high sensitivity of the electromagnetic excitations harmonic and spatial content to slight design modifications. However, this sensitivity can be so high that slight geometric deviations of the magnetic active parts within the

M. Jeannerot is with Vibratec, 28 chemin du petit bois, BP36, F-69131 Ecully Cedex, France, Univ. Bourgogne Franche Comté, FEMTO-ST Institute, CNRS/UFC/ENSMM/UTBM, Department of Applied Mechanics, 24 Rue de l'épitaphe, 25000, Besançon, France and Université de Technologie de Compiègne, CNRS, FRE 2012 Roberval, Centre de recherche Royallieu, 60203 Compiègne, France (e-mail : martin.jeannerot@vibratec.fr)

J.-B. Dupont and P. Bouvet are with Vibratec, 28 chemin du petit bois, BP36, F-69131 Ecully Cedex, France (e-mail: jeanbaptiste.dupont@vibratec.fr, pascal.bouvet@vibratec.fr) manufacturing tolerances can lead to very high variations of the electromagnetic excitations spectral content and thus to the loss of the radiated nois ereductions achieved by optimization. For such cases where determinis tic optimization is not suited, a robust optimization method is presented. It ensures, when considering random deviation of the uncertain parameters, to converge towards a design with a low average noise level, and a low variability. After describing the simulation methodology, the deterministic and robust optimization methods are described and applied to minimize the noise radiated by automotive traction motors.

\section{Mult IPHYSICAL SiMULAT ION OF ELECTRIC MOTORS NOISE}

The numerical simulation of the noise generation process in electric motors requires the modelling of phenomena belonging to different fields of physics. The noise generation process is summarized on Fig. 1.

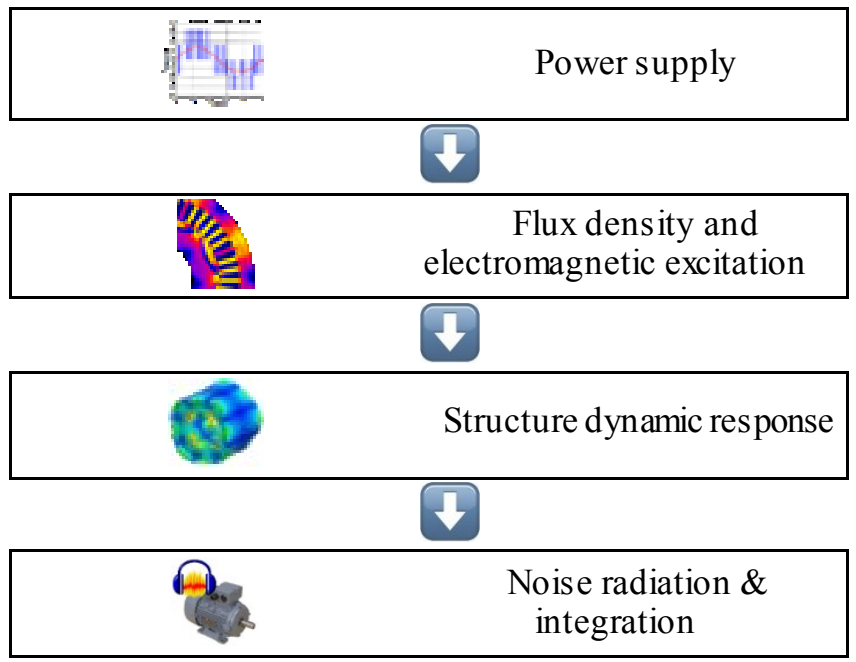

Fig. 1. Overview of the noise generation process in electric motors.

It can be divided into four steps:

- The supply of the motor by Pulse Width Modulation (PWM) of the supply voltage leads to the appearance of high order harmonics in the currents.

- These current harmonics, combined with the stator

E. Sadoulet-Reboul and M. Ouisse are with Univ. Bourgogne Franche Comté, FEMTO-ST Institute, CNRS/UFC/ENSMM/UTBM, Department of Applied Mechanics, 24 Rue de l'épitaphe, 25000, Besançon, France (e-mail: Emeline.Sadoulet-Reboul@univ-fcomte.fr ,morvan.ouisse@femto-st.fr)

V. Lanfranchi is with Université de Technologie de Compiègne, CNRS, FRE 2012 Roberval, Centre de recherche Royallieu, 60203 Compiègne, France (e-mail : vincent.lanfranchi@utc.fr) 
and rotor geometry and with the windings distributions, result in harmonic contributions in the airgap fluxdensity, and as a consequence to dynamic contributions in the radial and tangential Maxwell pressures, which constitute the prevailing electromagnetic excitation in electric motors, as stated in [7].

- The electromagnetic excitations apply to the stator and the rotor and cause vibrations, with an amplitude depending on the modal basis and damping of the powertrain structure, and on the amplitude, frequency and spatial distribution of the electromagnetic excitations.

- Depending on the operating deflection shapes and the vibration frequencies, the structure will prove to be more or less prone to radiating noise.

An overview of a 3-step multiphysical calculation scheme based on finite element models is given on Fig. 2.

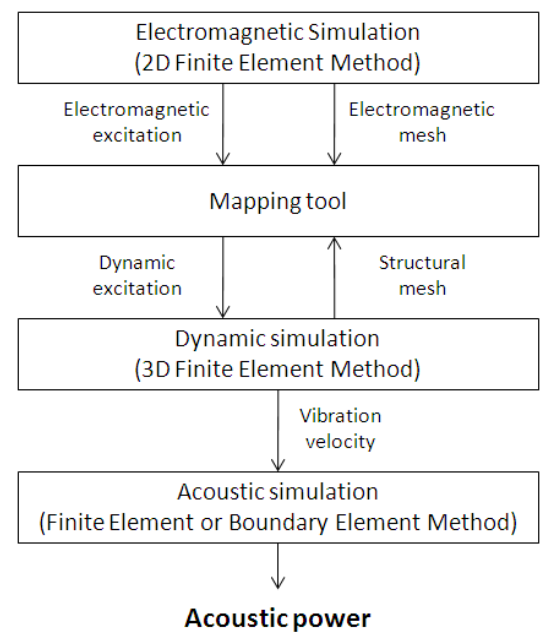

Fig. 2. Basic principle of the multiphysical simulation methodology.

The motor is first modelled using the electromagnetic $2 \mathrm{D}$ finite element method. At this stage, the two first steps of the noise generation process depicted on Fig. 1 are considered, since the supply conditions, the geometric design, the material properties and potential defects such as eccentricity are modelled. From this simulation, the radial and tangential flux densities are calculated along the air gap (as illus trated by Fig. 3 ), for different positions of the rotor.

The Maxwell pressures applying to the stator all along the airgap can then be calculated using

and

$$
\sigma_{\mathrm{r}}=\frac{1}{2 \mu_{0}}\left(\mathrm{~B}_{\mathrm{r}}^{2}-\mathrm{B}_{\mathrm{t}}^{2}\right)
$$

$$
\sigma_{\mathrm{t}}=\frac{1}{\mu_{0}}\left(\mathrm{~B}_{\mathrm{r}} \mathrm{B}_{\mathrm{t}}\right)
$$

where $\sigma$ is the surface force density, $B$ is the magnetic flux density, $\mu_{0}$ is the magnetic permeability of vacuum, and $r$ and $t$ denote radial and tangential components.

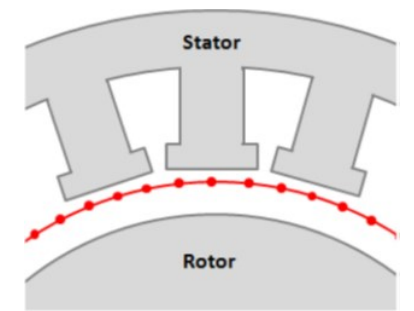

Fig. 3. Calculation points of the Maxwell pressure inside the airgap.

After converting the Maxwell pressure results from timedomain excitations to frequency domain excitations, they are projected onto the structural mesh of the powertrain. This process is performed using a dedicated mapping tool, dealing with the electromagnetic and structural meshes of different sizes and converting the 2D excitations calculated using the electromagnetic simulation into 3D excitations. The dynamic response of the structure is then calculated by modal frequency response. The modal basis of the powertrain structure is first extracted, and the dynamic response of each mode under the effect of electromagnetic excitations is calculated. Theoperating deflection shape is then obtained by summing the contribution of each mode. Some guidelines on the modelling of laminated stators are given in [8].

The last step of the procedure is about the estimation of the noise radiated by the machine, caused by the interaction of the vibrating structure with the surrounding air. The noise can be estimated from the vibration velocities of the motor's outer skin, either by time consuming but accurate numerical methods, such as acoustic finite element method (FEM) or boundary element method (BEM), or by using much faster analytical methods.

\section{DETERMINISTIC MULTI-CRITERIA OPTIMIZATION APPROACH}

\section{A. Description of the approach}

An optimization approach can be implemented at each step of the noise generation process depicted in Fig. 1:

- Optimization of the power supply and control strategy [3],

- Optimization of the electromagnetic design (number of poles, number of slots, shape and position of the magnetic active parts) [3],

- Optimization of the structure design [3,9],

- Optimization of the machine integration to reduce the propagation of vibration and sound inside and out of the vehicle [3].

The optimization method presented in this paper focuses on the optimization of the electromagnetic design. It aims at changing the geometry of the active magnetic parts in order to reduce the level of some electromagnetic excitations contributions which appear to be the cause of high noise levels. The amplitudes of the Maxwell pres sures contributions which are responsible for the noise in electric motors are very sensitive to electromagnetic design parameters such as the shape of the rotor poles or stator teeth. Therefore, a major 
benefit of this kind of optimization is that the geometrical changes applied to the design are small from a mechanical point of view, and they do not imply any significant increase of the motor's mass or additional cost.

The principle of this method is to use a simulation workflow following the same weak coupling principle as that described in Fig. 2, enabling for the estimation of the noise radiated by an electric motor for a given set of input parameters. The noise level radiated by the motor, or another criterion which must be reduced to improve the vibroacoustic behavior of the motor, is defined as the cost function of an optimization algorithm. This algorithm aims at minimizing this cost function by modifying some design parameters in the electromagnetic model.

Moreover, it is essential to guaranty that the design modifications resulting in the vibratory or acoustic level reduction do not deteriorate the overall electromechanical performance of the motor. For that purpose, constrained optimization is carried out. As depicted on Fig. 4, from a single electromagnetic simulation, not only the vibroacoustic behavior of the motor, but also its efficiency, its thermal behavior or its torque performance can be computed. As a consequence, the noise radiated by electric motors can be optimized at the same level as the aforementioned performance criteria.

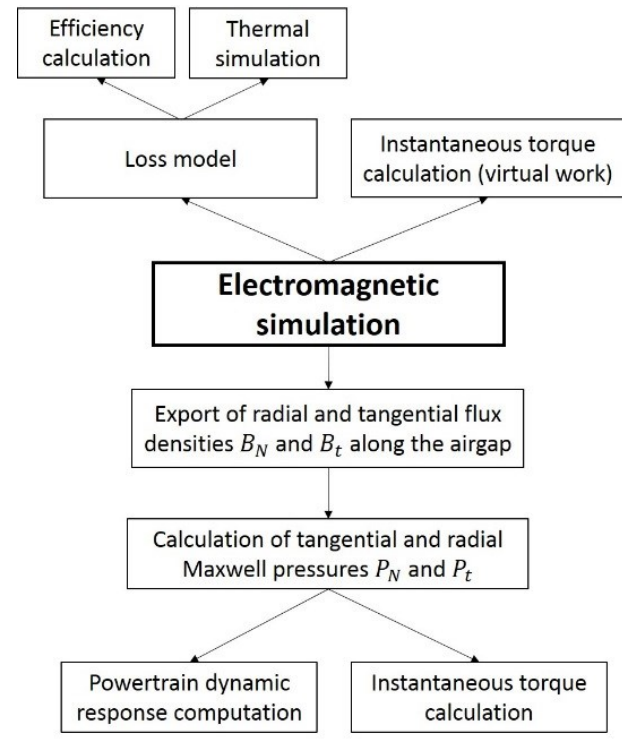

Fig. 4. Objective and constraint function possibilities from a common electromagnetic simulation.

Most of the time, this optimization method is used to reduce the vibratory or acoustic levels of the motors without deteriorating the overall performance. However, they can equally be used to maximize the overall performance without increas ing the vibratory or acoustic level, or to find a trade-off both improving the overall performance and decreasing the vibratory or acoustic level.

\section{B. Applications}

1) Optimization of a 10-pole permanent magnet synchronous motor

In the first practical case, the aim is to reduce the noise radiated by the automotive traction 10-poles interior permanent magnet synchronous motor (IPMSM) with Vshaped magnets depicted in Fig. 5. Because of their high torque density, high efficiency and good reliability, these motors are commonly used for automotive traction.

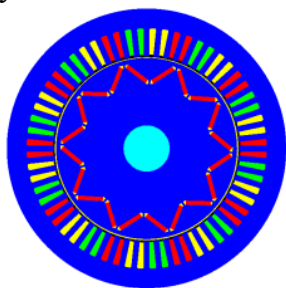

Fig. 5. Geometry of the initial PMSM

The objective of the optimization is to minimize the acoustic power level of the motor without decreasing its mean torque. The optimization should als o ensure that torque ripple is not increased, as it can lead to NVH is sues because of the excitation of other components of the mechanical drive or the excitation of overall bending modes of the powertrain.

Before running the optimization, a diagnosis of the motor's dynamic behavior must be performed in order to identify the critical motor speeds at which the noise should be reduced. This is done using the workflow described in Fig. 2.

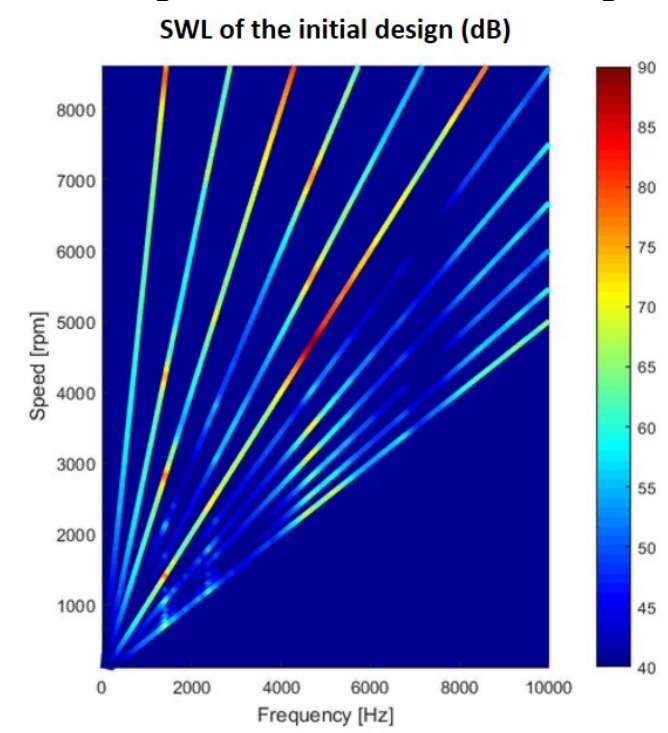

Fig. 6. Campbell diagram of the initial IPMSM Sound Power Level

Fig. 6 shows a Campbell diagram of the initial IPMSM design's Sound Power Level (SWL). The engine orders involved in the noise generation process are multiples of 10. The SWL related to engine order 60 is emerging around 4700 $\mathrm{rpm}$, because of the res onance of the stator's breathing mode under the effect of the Maxwell pres sure contribution related to engine order 60.

This diagnosis leads to an optimization aiming at reducing the noise level at the speed where the noise and vibrations are prevailing, i.e. at $4700 \mathrm{rpm}$. For this purpose, the cost function is defined as the acoustic power level at the engine speed of $4700 \mathrm{rpm}$.

To ensure that the torque performance is not deteriorated, some inequality constraints are also defined, so that the mean torque produced by the motor is not reduced and torque ripple is not increased in comparis on with initial design. 


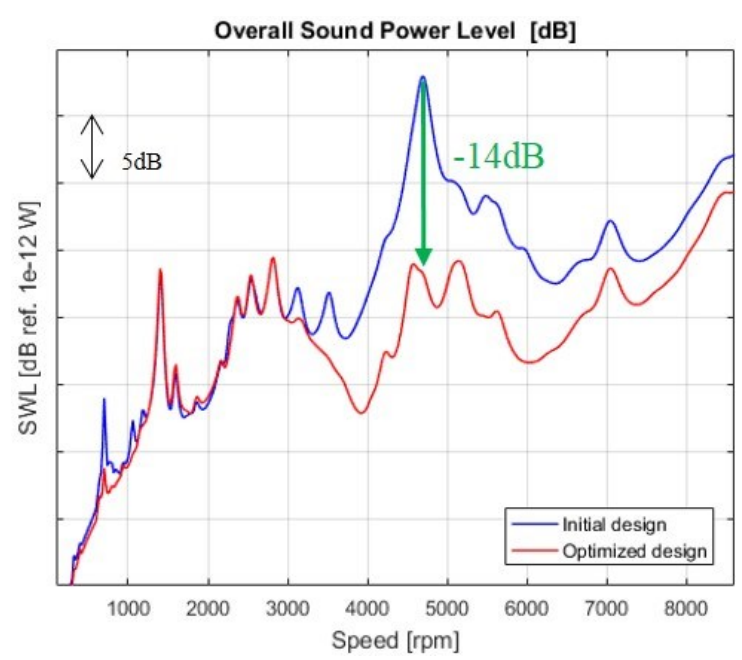

Fig. 7. Comparison of the SWL of the IPMSM initial and optimized designs

On Fig. 7, the results show a very significant $14 \mathrm{~dB}$ decrease of the SWL at the critical speed of the motor. More generally the noise level is reduced over the full speed range from $3000 \mathrm{rpm}$ to $8600 \mathrm{rpm}$, while it remains almost unchanged under $3000 \mathrm{rpm}$. This reduction was achieved by small changes on the shape of the rotor poles depicted on Fig. 8.

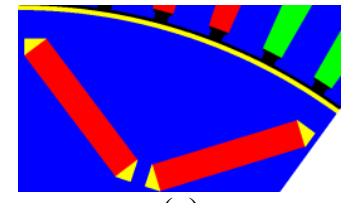

(a)

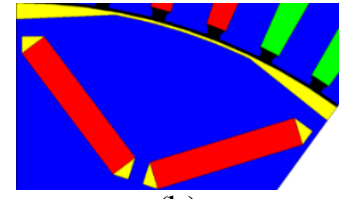

(b)
Fig. 8. (a) IPMSM initial design, (b) IPMSM optimized design

The noise could also be reduced under $3000 \mathrm{rpm}$ by performing multi-objective optimization aiming at reducing the noise at different motor speeds, at the risk of achieving lower reduction at the critical speed of $4700 \mathrm{rpm}$ because a trade-off design must then be found.

Fig. 9 and Fig. 10 show the mean torque and instantaneous torque curves for the initial and optimized designs.

Table I compares the mean torque and torque ripple values at $1000 \mathrm{rpm}$. The constraints are res pected, because there is no decrease of the mean torque, and no increase of torque ripple. The optimization even brought some improvement regarding these two criteria.

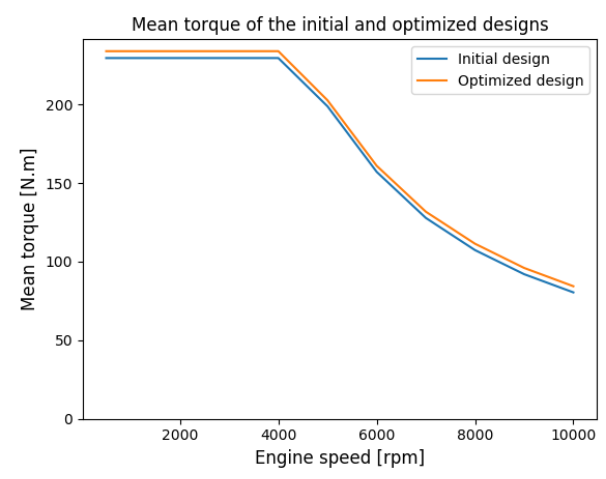

Fig. 9. Comparison of the mean torque of the initial and optimized IPMSM at maximum power

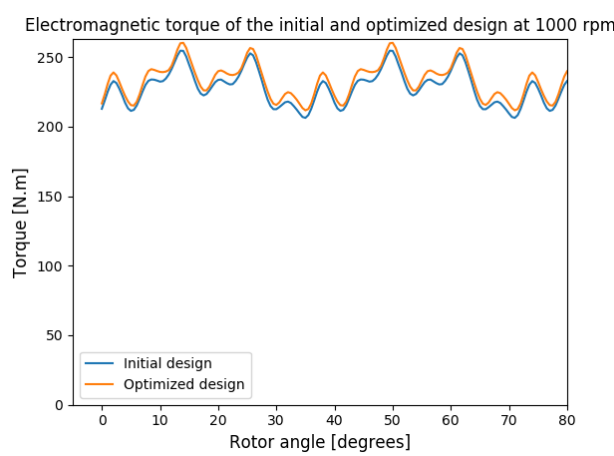

Fig. 10. Comparison of the instantaneous torque of the initial and optimized IPMSM at maximum power

TABLE I

COMPARISON OF MEAN TORQUE AND TORQUE RIPPLE AT 1000 RPM BEFORE AND AFTER OPTIMIZATION

\begin{tabular}{|c|c|c|}
\hline & Initial design & Optimized design \\
\hline $\begin{array}{c}\text { Mean torque } \\
\text { (N.m) }\end{array}$ & 228.7 & 233.7 \\
\hline Torque ripple (\%) & 10.5 & 10.4 \\
\hline
\end{tabular}

2) Optimization of a 8-pole permanent magnet synchronous motor

In this case, a complete powertrain composed of an 8-pole 48-s lot Permanent Magnet Synchronous Motor (PMSM), its housing and mounts, the gearbox housing and the power electronics unit must be optimized. The following is sue is faced: torque ripple causes the resonance of a powertrain overall bending mode. This is a critical issue because this resonance occurs at low speeds, between 500 and $3000 \mathrm{rpm}$, where the electromagnetic noise radiated by the powertrain is prevailing in comparis on with aerodynamic and rolling noise. Moreover, the modal frequency of the overall bending mode whose shape is prone to excited by torque ripple is located around $1000 \mathrm{~Hz}$. When a resonance of this mode occurs, the powertrain structure radiates noise at $1000 \mathrm{~Hz}$, a frequency to which the human ear is particularly sensitive.

As any periodic function, the instantaneous torque created by the motor can be expressed in the frequency domain using Fourier series decomposition. Engine orders 24, 48 and 96 mainly contribute to torque ripple, and they cause the resonance of the overall bending mode at different engine speeds. Another particularity of the motor is that its rotor is skewed. It is made of 4 parts of equal length along its axis: the first part being the reference, the second and third parts are identical and shifted by $3.75^{\circ}$ while the fourth one has the same orientation as the reference part. As a consequence, neglecting the side effects, the electromagnetic excitations are determined by using a 2D electromagnetic model for each section independently. To simplify the simulation process which must be performed at each cost function evaluation required by theoptimization, the objective of the optimization is to directly minimize the torque ripple contributions related to engine orders 24,48 and 96 at the engine speed at which they reach the frequency of $1000 \mathrm{~Hz}$ and provoke the resonance of the overall bending mode, i.e. at $2500 \mathrm{rpm}$ for engine order 24, $1250 \mathrm{rpm}$ for engine order 48 and $625 \mathrm{rpm}$ for engine order 96 . At the same time, attention must as always be paid to the mean torque of the motor so that it is notreduced during the optimization process. This is done by adding an 
inequality constraint guaranteeing that the mean torque of the optimized design, with no change of the supply currents, remains at the same level as that of the initial design.

Using the same optimization algorithms as for SWL reduction, significant torque ripple reductions can be achieved for the targeted engine orders at their critical speeds.

As a result, as depicted in Fig. 11, the optimized design produces a much smoother torque.

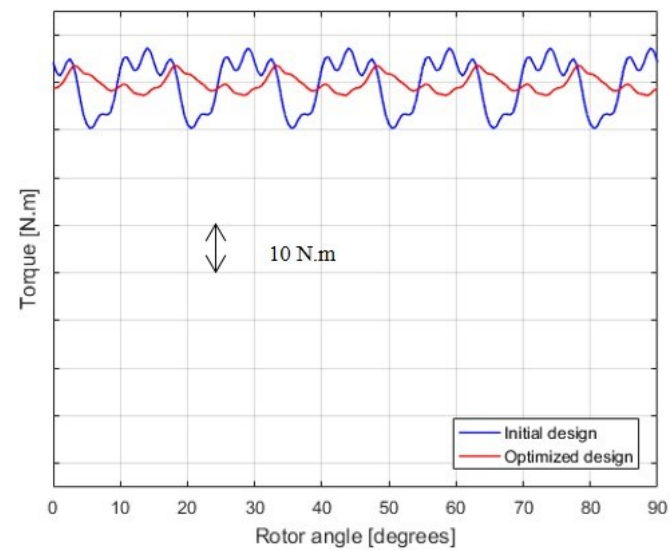

Fig. 11. Instantaneous torque comparison for initial and optimized designs at $1250 \mathrm{rpm}$

The torque ripple is significantly reduced for the optimized design, while the mean torque is unchanged. The amplitude reductions of torque engine orders 24,48 and 96 can be expressed in decibels using

$$
R_{D B}=20 \log _{10}\left(\frac{T_{h_{\text {optimized }}}}{T_{h_{\text {initial }}}}\right) \text {, }
$$

where $R_{D B}$ is the reduction in $\mathrm{dB}, T_{h_{\text {optimized }}}$ is the amplitude of the $h$ th torque engine order produced by the optimized design and $T_{h_{\text {initial }}}$ is the amplitude of the $h$ th torque engine order produced by the initial design.

These torque ripple reductions are summarized in Table II. The abbreviation e.o. stands for engine order.

TABLE II

REDUCTIONS OF THE NUMERICAL TORQUE AMPLITUDE LEVELS IN COMPARISON WITH THE INITIAL DESIGN

\begin{tabular}{|c|c|c|c|}
\hline $\begin{array}{c}\text { Engine order and } \\
\text { critical speed }\end{array}$ & $\begin{array}{c}\text { e.o. } 24 \mathrm{at} \\
2500 \mathrm{rpm}\end{array}$ & $\begin{array}{c}\text { e.0. } 48 \mathrm{at} \\
1250 \mathrm{rpm}\end{array}$ & $\begin{array}{c}\text { e.o. } 96 \mathrm{at} \\
625 \mathrm{rpm}\end{array}$ \\
\hline $\begin{array}{c}\text { Reduction of the } \\
\text { torque harmonics } \\
\text { (simulation) }\end{array}$ & $9.1 \mathrm{~dB}$ & $7.5 \mathrm{~dB}$ & $11.2 \mathrm{~dB}$ \\
\hline
\end{tabular}

As the resonance of the overall bending mode due to torque ripple excitation is prevailing over the other phenomena between 500 and $3000 \mathrm{rpm}$, expressing the reductions achieved for each torque engine order in $\mathrm{dB}$ gives an accurate estimation of the SWL reductions to be expected. As a consequence, the SWLreductions achieved in this case should be close to the torque engine order 48 level reduction values presented in Table II.

The effect of these modifications on the motor's SWL is calculated using the complete simulation workflow described on Fig. 2 and validates the reductions expected when considering torque harmonics. On this basis, a prototype has been built. The experimental results provide the reductions synthetized in Table III. These reduction of the near field acoustic pressure overall level are even higher than those estimated by the simulations, and they validate the optimization method.

TABLE III

REDUCTIONS OF THE MEASURED NEAR FIELD OVERALL ACOUSTIC LEVELS IN COMPARISON WITH THE INITIAL DESIGN

\begin{tabular}{|c|c|c|c|}
\hline Motor speed & $\begin{array}{c}2500 \\
\mathrm{rpm}\end{array}$ & $\begin{array}{c}1250 \\
\mathrm{rpm}\end{array}$ & $\begin{array}{c}625 \\
\mathrm{rpm}\end{array}$ \\
\hline $\begin{array}{c}\text { Reduction of the near } \\
\text { field acoustic pressure } \\
\text { (experimental overall level) }\end{array}$ & $11 \mathrm{~dB}$ & $18 \mathrm{~dB}$ & $17 \mathrm{~dB}$ \\
\hline
\end{tabular}

In this case, the experimental results show that the optimized design is probably robust, although several prototypes should be built or a numerical sensitivity analysis should be conducted to quantify the variability of the optimization cost function when considering geometric deviation.

However, several optimizations starting from different designs have been necessary to reach this optimized design. Many optimizations have converged towards designs achieving very high reductions of the torque engine order 48 level, which reveal to be non-robust minima. Performing robust optimization can ensure the convergence towards a robust minimum.

\section{ROBUST OPTIMIZATION APPROACH}

\section{A. Description of the approach}

The aim of robustness in the case of electric motors acoustics is to minimize the impact of uncertainty sources which cannot be eliminated, i.e. mainly geometry and material properties deviation, as well as control inaccuracies, on the vibratory and acoustic behavior of the motor.

The two main forms of robust optimization are [10]:

- A worst case optimization, aiming at minimizing the cost function when the set of uncertain parameters maximizing this cost function is taken [11].

- A probabilistic optimization, considering the cost function as a random function subject to random uncertain parameters following given density functions [12]-[13]. The aim is then to minimize the mean value of this randomcost function, as well as its variability.

The worst case optimization leads to conservative results, and it is rather intended to critical applications where no failure due to the uncertainty sources can be accepted. For the purpose described in this paper, the reduction of the noise radiated by the motor for a wide majority of the motors is targeted, but having a few manufactured motors for which the noise reduction is not as good as expected is not critical. The probabilistic approach is therefore adopted to robustly minimize the acoustic levels of the electric motors.

To evaluate the robustness of a given design using this probabilistic approach, the deterministic cost function is expressed in the following way:

$$
f=f(x+\delta) \text {, }
$$


where $x=\left(x_{1}, \ldots, x_{N}\right)^{T}$ is the set of design parameters, which are fixed for the given design, and $\delta=\left(\delta_{1}, \ldots, \delta_{M}\right)^{T}$ is the set of uncertain parameters, which are considered as random parameters.

A design of given parameters $x$, and for which all the $M$ uncertain parameters $\delta_{i}=0$ are zero, is called nominal design. However, no manufactured design perfectly respects the nominal design because they are all subject to deviations modelled by the uncertain parameters $\delta_{i} \neq 0$.

In this paper, the assumption is made that the uncertain parameters $\delta_{i}$ follow a normal distribution $\mathcal{N}\left(0, \sigma_{i}\right)$. Their expectation is set to zero, because systematic deviation can be considered by modifying the nominal design. Their standard deviations $\sigma_{i}$ can be estimated from experimental data when measurements are available, or if not, by taking a value of the same order of magnitude as the tolerances, which are usually known.

Some Monte-Carlo samplings are then generated, providing different sets of uncertain parameters $\delta$, and $f(x+$ $\delta$ ) is computed for each sample. The mean value $\mu_{f}$ and the standard deviation $\sigma_{f}$ of $f$ over all samples are the robustness indicators.

The function to minimize to perform robust optimization is then:

$$
\alpha \mu_{f}+(1-\alpha) \sigma_{f},
$$

where $\alpha \in[0,1]$ is a scalar weighting factor defining the trade-off to pursue between mean value and standard deviation minimization. In the rest of the paper, this function is called robust cost function.

\section{B. Application}

The determinis tic optimization of the 8-pole PMSM leads to the satis factory results presented in Table II and Table III. However, many optimizations have been run and some of themhave converged towards designs providing very large but also non robust reductions of the torque engine order 48 level. The robustness of one of these non-robust designs is evaluated, and the robust optimization methodology is then applied.

The calculation of the output torque of this skewed PMSM is a relatively long process because of the size of the electromagnetic model and the necessity to model several sections of the motor to account for the skewing effect. This computation time limitation, as well as the fact that the torque engine order 48 is very significantly more variable than the other engine orders when uncertainties are considered, lead to the decision to focus on this engine order 48 at the engine speed of $1250 \mathrm{rpm}$ for this example.

To quantify the robustness of the deterministically optimized non-robust design, the mean value $\mu_{f}$ and standard deviation $\sigma_{f}$ of its torque engine order 48 level are calculated.

The number of samples of the Monte-Carlo sampling is limited by the time necessary to compute the torque for each sample. In this case, 200 samples are generated. This number seems appropriate, since the theoretically zero mean value of each parameter is within the range $\left[-\frac{\sigma_{i}}{50}, \frac{\sigma_{i}}{50}\right]$, while the maximum relative error between a standard deviation calculated over the 200 samples and its theoretical value is of $5 \%$.

The results of the robustness analysis are presented in Table IV. While the nominal design achieves a reduction of $20 \mathrm{~dB}$ in comparis on with the initial design, the 200 samples provide a mean reduction of $7.6 \mathrm{~dB}$. Moreover, the high standard deviation means that the torque engine order 48 level, and thus SWL, are very variable, and that while some manufactured motors are significantly less noisy than the initial design, a non-negligible amount of them are as noisy as the initial design or even louder.

TABLE IV

RESULTS OF THE ROBUSTNESS ANALYSIS OF THE DETERMINISTIC NON-

\begin{tabular}{|c|c|c|}
\hline $\begin{array}{c}\text { e.o. } 48 \text { level } \\
\text { reduction of nominal } \\
\text { design with respect to } \\
\text { initial design }\end{array}$ & $\begin{array}{c}\text { e.o. } 48 \text { level mean } \\
\text { reduction with } \\
\text { respect to initial } \\
\text { design }\end{array}$ & $\begin{array}{c}\text { e.o. } 48 \text { level } \\
\text { standard } \\
\text { deviation }\end{array}$ \\
\hline $20.0 \mathrm{~dB}$ & $7.6 \mathrm{~dB}$ & $7.0 \mathrm{~dB}$ \\
\hline
\end{tabular}

The robust optimization methodology presented in this paper can be useful to avoid such non-robust designs and to converge directly towards a robustly silent design. For this purpose, the robust cost function defined in (4) is minimized. The weighting factor $\alpha$ is set to 0.5 , what means that the same importance is given to the reduction of the mean value and the standard deviation of the torque engine order 48 level. Moreover, an inequality constraint imposing no mean torque reduction must be added. As the mean torque of the motor is significantly less sensitive to uncertainties than their vibroacoustic behavior, the inequality constraint only guarantees that the nominal optimized design is not subject to any mean torque reduction when compared with that of the initial design.

The results of this optimization are depicted in Table V. The design resulting from this optimization provides a much larger mean reduction of the engine order 48 level, with a much lower standard deviation.

Both mean value and standard deviation are significantly reduced in comparison with those of the deterministically optimized design which is not robust. These results show that probabilistic robust optimization can be applied to optimize electric motors when deterministic optimization converges towards non-robust designs. This method has been applied to minimize only the torque engine order 48 at $1250 \mathrm{rpm}$, because it is the objective which is subject to the highest variability. The robust optimization method being time consuming, because computing the values of $\mu_{f}$ and $\sigma_{f}$ requires several evaluations of the deterministic cost function $f$, performing a robust multi-objective optimization aiming at minimizing the torque engine orders 24,48 and 96 at their respective critical engine speeds of $2500 \mathrm{rpm}, 1250 \mathrm{rpm}$ and $625 \mathrm{rpm}$ would require a long computation time. An alternative could be to define a multiobjective optimization aiming at minimizing both mean value and standard deviation of the torque engine order 48 at $1250 \mathrm{rpm}$ when uncertainties are considered, and at minimizing the torque engine orders 24 
and 96, which are not subject to a high variability when uncertainties are considered, for the nominal design only.

TABLE V

COMPARISON OF THE ROBUSTNESS ANALYSES OF THE DETERMINISTICALLY OPTIMIZED NON-ROBUST DESIGN AND THE ROBUSTLY OPTIMIZED DESIGN

\begin{tabular}{|c|c|c|}
\cline { 2 - 3 } \multicolumn{1}{c|}{} & $\begin{array}{c}\text { e.o. 48 level mean } \\
\text { reduction with respect } \\
\text { to initial design }\end{array}$ & $\begin{array}{c}\text { e.o. } 48 \text { level } \\
\text { standard } \\
\text { deviation }\end{array}$ \\
\hline $\begin{array}{c}\text { Deterministically } \\
\text { optimized non } \\
\text { robust design }\end{array}$ & $7.6 \mathrm{~dB}$ & $7.0 \mathrm{~dB}$ \\
\hline $\begin{array}{c}\text { Robustly } \\
\text { optimized design }\end{array}$ & $15.0 \mathrm{~dB}$ & $2.14 \mathrm{~dB}$ \\
\hline
\end{tabular}

\section{CONCLUSION}

The multiphysical numerical modelling of electric motors, coupling electromagnetic, dynamic and acoustic models, enables for the accurate estimation of their vibroacoustic behavior, but can also be used to reduce their vibroacoustic disturbances using optimization algorithms. These optimizations can lead to large reductions of the vibratory or acoustic levels, while overall performance remains unchanged.

In some cases, after performing a deterministic optimization minimizing the vibration or noise levels of a nominal design, the robustness analysis shows that the resulting optimized design has an acceptable variability when the deviation of uncertain parameters is considered. Otherwise, probabilistic robust optimization methods can be used. The efficiency of these methods, to reduce the mean value of acoustic or vibratory levels as well as their variability in an uncertain context, is demonstrated in this paper. Theyare however time consuming, and their use can be restricted to cases where no robust design can be found by deterministic optimization. Moreover, to reduce the time consumption of the method, it is necessary to select only design parameters and uncertain parameters having a significant effect on the criteria to minimize.

\section{REFERENCE}

[1] P. Pellerey, V. Lanfranchi and G. Friedrich, "Coupled numerical simulation between electromagnetic and structural models, influence of the supply harmonics for synchronous machine vibrations," IEEE Transactions on Magnetics, vol. 48, no. 2, pp. 983-986, Feb. 2012

[2] A. Tan-Kim, V. Lanfranchi, S. Vivier, J. Legranger and F. Palleschi, "Vibro-Acoustic Simulation and Optimization of a Claw-Pole Alternator," IEEE Transactions on Industry Applications, vol. 52, no. 5, pp. 3878-3885, Sept.-Oct. 2016

[3] J.-B. Dupont. and H. Saucy, "Noise radiated by electric motors: simulation process and overview of the optimization approaches", 2017 Automotive Acoustics Conference, Zurich, Switzerland, pp.107-121.

[4] P. Kotter, D. Morisco, M. Boesing, O. Zirn and K. Wegener, "NoiseVibration-Harshness-Modeling and Analysis of a Permanent-Magnetic Disc Rotor Axial-Flux Electric Motor," IEEE Transactions on Magnetics, vol. 54, no. 3, pp. 1-4, March 2018.

[5] J. Hallal, A. H. Rasid, F. Druesne and V. Lanfranchi, "Comparison of radial and tangential forces effect on the radial vibrations of synchronous machines," 2019 IEEE International Conference on Industrial Technology (ICIT), Melbourne, Australia, 2019, pp. 243-248.

[6] J.-B. Dupont, P. Bouvet and J.-L. Wojtowicki, "Simulation of the Airborne and Structure-Borne Noise of Electric Powertrain: Validation of the Simulation Methodology," SAE Technical Paper 2013-01-2005, 2013.

[7] J.-B. Dupont, P. Bouvet and L. Humbert, "Vibroacoustic simulation of an electric motor: methodology and focus on the structural FEM representativity," 2012 XXth International Conference on Electrical Machines, Marseille, 2012, pp. 3027-3033.

[8] P. Millithaler, E. Sadoulet-Reboul, M. Ouisse, J.-B. Dupont and N Bouhaddi, "Structural dynamics of electric machine stators: Modelling guidelines and identification of three-dimensional equivalent material properties for multi-layered orthotropic laminates," Journal of Sound and Vibration, vol. 348, pp. 185-205, 2015.

[9] P. Millithaler, J.-B. Dupont, M. Ouisse, E. Sadoulet-Reboul and N Bouhaddi,, "Viscoelastic property tuning for reducing noise radiated by switched-reluctance machines," Journal of Sound and Vibration, vol. 407, pp. 191-208, 2017.

[10] H.-G. Beyer, B. Sendhoff, "Robust optimization - a comprehensive survey," Computer Methods in Applied Mechanics and Engineering, vol. 196, pp. 3190-3218, July 2007.

[11] Y. Ben-Haim, "A non-probabilistic measure of reliability of linear systems based on expansion of convex models," Structural Safety, vol. 17, pp. 91-109, 1995.

[12] K. H. Hwang, K. W. Lee and G. J. Park, "Robust optimization of an automobile rearview mirror for vibration reduction," Structural and Multidisciplinary Optimization, no. 21, pp. 300-308, 2001.

[13] C. Zang, M. Friswell, J. Mottershead, "A review of robust optimal design and its application in dynamics," Computers and Structures, no. 83, pp. 315-326, Jan. 2005.

\section{BIOGRAPHIES}

M. Jeannerot was born in France in 1995. He received a M.E from the Université de Technologie de Compiègne (France) in 2018. He is currently pursuing his Ph.D. degree at the Université de T echnologie de Compiègne, in partnership with the FEMTO-ST Institute and Vibratec. His research interests are related to vibroacoustic optimization of electric motors.

J.-B. Dupont was born in France in 1980. He received the M.Sc. and Ph.D. degrees from Ecole Centrale de Lyon, Lyon, France, in 2003 and 2007 respectively. He joined Vibratec, Ecully, France, in 2007. He is now the Chief Technical Officer and his main skills are related to computational acoustics, vibro-acoustics and dynamics. Since 2009, he is in charge of the development of simulation methods of the noise and vibration of electrical machines.

E. Sadoulet-Reboul received a Ph.D. from Ecole Centrale de Lyon in 2005. She is currently associate professor at ENSMM, Université de Bourgogne Franche Comté, doing her research at FEMTO-ST Department of Applied Mechanics on Structural Dynamics, Vibroacoustic and Smart Structures.

M. Ouisse was born in France in 1975. He received a Ph.D. from INSA Lyon in 2002. He is currently full professor at ENSMM, Université de Bourgogne Franche-Comté, doing his research at FEMTO-ST Department of Applied Mechanics on Structural Dynamics, Vibroacoustics and Smart Structures.

V. Lanfranchi received his $\mathrm{Ph}$. D. degree in electrical engineering from the University of Reims (France) in 2000. He is now full professor at the Université de Technologie de Compiegne. His teaching areas are electrical engineering and mechatronic. He was a researcher in the LEC laboratory (Laboratoire d'Electromecanique de Compiegne) from 2001 to 2017. He is now head of M2EI (mechatronic, energy, electricity, integration) team in the ROBERVAL Laboratory at UTC. His main research interest is design of electromechanical systems for energy conversion with multi-physic approach. It also focuses on harmonic behavior including converter-machine interactions and Pulse Width Modulation strategies.

P. Bouvet was born in France in 1965. He received the M.Sc. from the Université de Technologie de Compiègne in 1989 and Ph.D. at CSTB in 1993. He joined Vibratec, Ecully, France, in 1993. He is now the Executive Manager and his main skills are related to vibro-acoustics and dynamics for the automotive and railway industries. Since 2009, he has managed most of Vibratec's research projects dealing with the noise of electric drive systems (including e-motor and gearbox noise). 